\title{
Too Tight or Too Loose? The stringency of Mobility Restriction Policy Response by the Government of Sri Lanka against Covid-19
}

N.W.A.N.Y. Wijesekara ( $\square$ novil.wijesekara@gmail.com )

Disaster Preparedness and Response Division, Ministry of Health

H.D.B. Herath

Disaster Preparedness and Response Division, Ministry of Health

K.A.L.C. Kodithuwakku

Disaster Preparedness and Response Division, Ministry of Health

B.A.M.P. Bulathsinghe

Disaster Preparedness and Response Division, Ministry of Health

\section{Research Article}

Keywords: Covid-19, Government Response Stringency Index, Stringency Fatigues, Mobility, Policy

Response

Posted Date: December 14th, 2020

DOl: https://doi.org/10.21203/rs.3.rs-128156/v1

License: (9) (1) This work is licensed under a Creative Commons Attribution 4.0 International License.

Read Full License 


\section{Abstract}

The Covid-19 pandemic has demanded governments to respond through policy measures on health systems, restriction of community mobility, and economic recovery. Policy measures on mobility included international and local travel restrictions, closure of schools and workplaces, work from home, cancellation or restriction of public gatherings, close of public transport, and stay at home orders. Sri Lanka too has embraced several policy measures restricting community mobility to curtail the outbreak. This paper analyzes the trend of stringency of Covid- 19 mobility restriction policy response by the Government of Sri Lanka concerning its epidemiological trend, and with the same patterns observed in selected countries of the world. The Government Response Stringency Index (GRSI), a composite indicator developed by the Oxford Government Response Tracker (OxCGRT) group consisting of nine indicators based on publicly available data was used to track the stringency of policy measures related to mobility restrictions in Sri Lanka and the selected other countries. Besides, the daily number of Covid-19 cases in the same countries was analyzed. The results show that Sri Lanka was able to achieve $100 \%$ in the GRSI at the early stages of the outbreak, and most clusters it faced were curtailed under considerable high GRSI levels. GRSI values dropped to $26.85 \%$ just before the onset of the largest ever Minuwangoda Cluster, after which it was raised to $50 \%$. Comparing GRSI values and epidemiological pattern of Sri Lanka with three purposefully selected blocks of countries showed that its stringency to be comparatively lower than most of the countries studied, as per the end of the study period. It could be seen that the current GRSI values about the policy measures adopted by the government of Sri Lanka are suboptimal, compared to the level of risk based on the case trend that the country is exposed to, as of $30^{\text {th }}$ November 2020. These findings provide evidence towards the implementation of more stringent mobility control measures on an urgent basis, at least until the case number starts to fall.

\section{Introduction}

Exactly one year on, from the discovery of the first case of SARS-COVI 2 virus infection in China, the world community has witnessed an unprecedented spread of the infection transcending all geographical, social and ethno-religious boundaries. As of $30^{\text {th }}$ November 2020, World Health Organization (WHO) has estimated a staggering 62,195,274 COVID-19 cases around the globe and 1,453,355 fatalities (World Health Organization 2020b). According to WHO world regions, the Americas contribute to the lion share of the global cases with 24,563,600 cases, whereas the South East Asia Region (SEARO) records 10,367,553 cases. India has recorded nearly 9 million cases. The United States of America (USA) seems to be the hardest hit in case of fatalities, recording 266,932 deaths as of $30^{\text {th }}$ November 2020 . As per the latest available figures around 220 countries, areas or territories are affected by the COVID-19 pandemic. As of $30^{\text {th }}$ November 2020, data from the Epidemiology Unit of the Ministry of Health, Sri Lanka records 23,484 cases with 116 deaths (Epidemiology Unit 2020).

As a Public Health Emergency of International Concern (PHEIC) and pandemic has demanded countries to respond in an unprecedented manner through interventions at the policy level to the tactical 
level (World Health Organization 2020a, 2020c). Some policy level decisions ranged from full lockdown of countries to implementation of selective aspects of restrictions (Erdbrink and Anderson 2020; FT Visual \& Data Journalism Team 2020). Policy level decisions varied in their technical domain as well. The first group of policies was essentially large-scale use of existing health system policies such as those on surveillance at Ports of Entry, quarantine, laboratory testing, treatment of positive cases, contact tracing, containment and wearing of face masks. The second group of policies, or containment and closure policies targeted restricting mobility of communities through school and workplace closure, cancellation of public gatherings, movement restrictions, and quarantine curfews. The third group of policies was economic policies focused on managing the adverse effects of certain policy decisions, for example, supporting the vulnerable communities who have been affected by the movement restrictions or financially supporting those who are affected due to lockdowns (Hale et al. 2020b). The policy decisions were meant to be implemented so that they would lead to actions, which would in return contribute to prevention and control of Covid-19. However, good policies may not bear good results because many other complex factors could complicate such policy decisions. For example, certain "good" policy decisions made by the government may not be implemented at all, while the others may lack mechanisms for their enforcement. Policies restricting the movement may be effective from the epidemiological point of view, however, from an economic point of view, they could be suicidal (Cross, $\mathrm{Ng}$, and Scuffham 2020; Ferraresi et al. 2020). Certain government systems too, for example, the health system, or legal system may have their challenges of adopting and implementing new and more radical policy decisions. On the other hand, most policy decisions demand adherence to them by the communities, which may largely be dependent on health literacy as well as civic literacy of the population. Hence, good policy decisions are not necessarily meant to be successful, nor they will assure that the Covid-19 caseload will come down as a result of them, at least in the short run (Potter and Harries 2006). The focus of this paper is on the second group of policies, namely those which were containment and closure policies, meant to reduce the mobility of communities, which was expected to reduce the transmission of the disease.

Across the globe, many governments have implemented different strategies to restrict the mobility of persons (FT Visual \& Data Journalism Team 2020). Some countries have declared full lockdown while others have resorted to selective elements, ranging from international and local travel restrictions, closure of schools and workplaces, work from home, cancellation or restriction of public gatherings, close of public transport, stay at home orders (Hale et al. 2020b). Governments have adopted a dynamic and iterative approach, in selecting all or some of the policy options available, to address the mobility restriction needs of the time. The Covid-19 status of a country can be measured, at least to a certain degree by the number of cases and deaths reported, even though it is much affected by the availability and coverage of testing facilities in a country (World Health Organization 2020b). Nevertheless, measuring the level of stringency at which the mobility restriction policies have been implemented in a country is a challenging task.

The Oxford Government Response Tracker (OxCGRT) group, among eighteen indicators that they collect globally through publicly available information government responses, uses nine indicators to track the 
stringency of the mobility restriction policies and measures (Hale et al. 2020a). These indicators are used to develop a composite indicator "Government Response Stringency Index" (GRSI) which could be used to track the status of policies and measures concerning mobility restrictions of a country over time, or to compare different countries across the time (Hale et al. 2020b).

Sri Lanka, an island nation in the Indian Ocean has implemented policies and measures addressing restricting mobility of the people during the Covid-19 pandemic, as a part of a comprehensive set of policy tools used targeting the health system, mobility restriction and economic recovery (Jayaratne, Arambepola, and Prathapan 2020). Sri Lanka has been able to successfully curtain several clusters of Covid-19 since the beginning of the year 2020, however, by November 2020, it is struggling to curtain a large Minuwangoda cluster and subclusters linked to it (Epidemiology Unit 2020). In this backdrop, it is essential to find reexamine the stringency of mobility restriction policy response mounted by the Government of Sri Lanka. The objective of this paper is to analyze the trend of stringency of Covid-19 mobility restriction policy response by the Government of Sri Lanka with its epidemiological trend, and in relation to the same patterns observed in selected countries of the world.

\section{Methodology}

\subsection{The Government Response Stringency Index (GRSI)}

To measure the stringency of mobility restriction policy response, the GRSI, developed by the Oxford Government Response Tracker (OxCGRT) group was used (Hale et al. 2020a). This group of researchers from Oxford University, though an extensive network of volunteers collects publicly available information about 8 indicators of government responses for Covid-19 (Refer Table 1).

Table 1 : Oxford Government Response Tracker Policy Categories and Indicators

\begin{tabular}{|l|c|c|}
\hline Policy Category & Number of indicators & Indicator Numbers \\
\hline Containment and Closure Policies & 8 & C1 - C8 \\
\hline Economic Policies & 4 & E1 - E4 \\
\hline Health System Policies & 6 & H1 - H6 \\
\hline
\end{tabular}

With the data gathered with the above 18 indicators, four sets of standard indices are generated. Each of these indices ranges from 1 to 100 (Refer Table 2).

Table 2 : Oxford Government Response Tracker Indicators, Area of Focus and Component Indicators 


\begin{tabular}{|c|c|c|}
\hline Indicator & Area of Focus & $\begin{array}{l}\text { Component } \\
\text { indicators }\end{array}$ \\
\hline $\begin{array}{l}\text { stringency } \\
\text { index }\end{array}$ & $\begin{array}{l}\text { Strictness of 'lockdown style' policies that primarily restrict } \\
\text { people's behavior }\end{array}$ & C1- C8, H1 \\
\hline $\begin{array}{l}\text { economic } \\
\text { support } \\
\text { index }\end{array}$ & income support and debt relief & E1 - E4 \\
\hline $\begin{array}{l}\text { containment } \\
\text { and health } \\
\text { index }\end{array}$ & $\begin{array}{l}\text { 'lockdown' restrictions and closures with measures such as } \\
\text { testing policy and contact tracing, short term investment in } \\
\text { healthcare, as well investments in vaccine }\end{array}$ & $\begin{array}{l}\text { C1- C8, } \\
\text { H1, H2, } \\
\text { H3, H6 }\end{array}$ \\
\hline $\begin{array}{l}\text { Overall } \\
\text { government } \\
\text { response } \\
\text { index }\end{array}$ & Overall government response & $\begin{array}{l}\text { C1-C8, E1 } \\
-\mathrm{E} 2, \mathrm{H} 1- \\
\mathrm{H} 6\end{array}$ \\
\hline
\end{tabular}

In this study, the GRSI, which was the original index that the OxGRT group developed was utilized. A point to note is that in addition to indicators measuring containment and closure, one indicator on public information campaigns is also included in the GRSI, probably highlighting the importance of such campaigns on viability of such mobility restriction efforts.

It should be highlighted that these indices are intended to record the strictness of government policies. They should not be interpreted as scoring the appropriateness of effectiveness of a particular country's response. A higher score in the index does not necessarily mean that the country's response is superior to those with a lower score since many other factors would come into play in the implementation of the policy in reality.

The GRSI calculated by simple averages of the individual component indicators.

$$
\text { GRSI }=\frac{1}{k} \sum_{j=1}^{k} I j \text {--------- Equation } 1
$$


$K=$ the number of component indicators in an index

$l_{j}=$ the sub-index score for an individual indicator

Different indicators (j) have different maximum values. Only some have flag variables $\mathrm{INj})$. Thus, each sub-index score had been calculated separately. The details of indicators that comprise GRSI are shown in Table 3.

Table 3: Government Response Stringency Index Details

\begin{tabular}{|l|l|l|l|}
\hline Indicator & Number & Max. value $(\mathrm{Nj})$ & Flag? (Fj) \\
\hline School closing & C1 & $3(0,1,2,3)$ & yes $=1$ \\
\hline Workplace closing & C2 & $3(0,1,2,3)$ & yes $=1$ \\
\hline Cancellation of public events & C3 & $2(0,1,2)$ & yes-1 \\
\hline Restriction of gatherings & C4 & $4(0,1,2,3,4)$ & yes $=1$ \\
\hline Close public transport & C5 & $2(0,1,2)$ & yes $=1$ \\
\hline Stay at home requirement & C6 & $3(0,1,2,3)$ & yes $=1$ \\
\hline Movement restriction & C7 & $2(0,1,2)$ & yes $=1$ \\
\hline International travel restriction & C8 & $4(0,1,2,3,4)$ & no=0 \\
\hline Public information campaigns & H1 & $2(0,1,2)$ & yes $=1$ \\
\hline
\end{tabular}

Each sub-index score $(I)$ for any given indicator $(j)$ on any given day $(t)$, is calculated by the function described in equation 2 :

$$
I_{j, t}=100 \frac{v_{j, t}-0.5\left(F_{j}-f_{j, t}\right)}{N_{j}}
$$

- the maximum value of the indicator $\left(N_{j}\right)$

- whether that indicator has a flag $\left(F_{j}=1\right.$ if the indicator has a flag variable, or 0 if the indicator does not have a flag variable)

- the recorded policy value on the ordinal scale $\left(v_{j, t}\right)$

- the recorded binary flag for that indicator $\left(f_{j, t}\right)$ 
This is used to normalize the different ordinal scales to produce a sub-index score between 0 and 100 to ensure that each full point on the ordinal scale is equally spaced. For indicators that do have a flag variable, if this flag is recorded as 0 (For example, if the policy is geographically targeted but not countrywide), then this is considered as a half-step between ordinal values.

\subsection{Data Sources and Timeframe}

The GRSI calculated data set by OxCGRT website from 23.01.2020 (the earliest date on which the data was available) and up to $30^{\text {th }}$ of November 2020 was downloaded (Hale et al. 2020a). The sub-indicator data for Sri Lanka was also downloaded from the OxCGRT website. The Covid-19 case data was obtained from the Our World in Data website (Roser et al. 2020)

\subsection{Countries of interest}

It was necessary to compare the GRSI and epidemiological pattern of Sri Lanka with some selected countries. Three Blocks of countries were selected for this purpose.

Block 1 - First contact countries: China and South Korea were selected as two proxies of the first countries that came into contact with the virus. Further, both countries had strong geopolitical and economic ties with Sri Lanka.

Block 2 - South Asian Association for Regional Corporation (SAARC) Countries. These countries had many socio-economic and cultural similarities to Sri Lanka, hence understanding their stringency policies could be useful. Since data from the Maldives was not available for GRSI in the data set, it was excluded. Thus Afghanistan, Bhutan, Bangladesh, India, Nepal, and Pakistan were studied.

Block 3 - The affluent countries. United States of America, the United Kingdom, Australia, and New Zealand were included.

The number of Covid-19 cases and the GRSI values for each country were plotted for the period from 23.01.2020 to 30.11.2020. The patterns were compared visually.

\section{Results And Discussion}

The GRSI consists of nine sub-indicators, eight on mobility restriction and one on public information campaigns. The distribution of the sub-indicators is shown in Figure 1.

As per Figure 1, it should be seen that at least for some periods, all indicators have reached the highest possible score, indicating that the country has been in full swing in the stringency of the mobility restriction measures. Some indicators, such as school closure, cancelation of public events, and restriction of international travel has been sustained for considerable time. Nevertheless, workplace closing, restriction of gatherings, public transport closing, staying at home requirements, and movement restrictions have been quite short lived. One interesting observation is that public education campaigns, 
which took a while to come to their fullest, continue at that level even to the end of the study period. The GRSI and Covid-19 New Case Occurrence over the study period for Sri Lanka are shown in Figure 2.

From Figure 2, it is evident that Sri Lanka has witnessed a rapid rise of the GRSI, reaching $100 \%$ by 27.03.2020. The GRSI remained at $100 \%$ till 17.04 .2020 , then a slow stepwise decline to $26.85 \%$ by 03.10.2020 was observed. However, the GRSI saw a rise to 34.26 over a day and remained so, until 02.11.2020 when it further increased up to $55.09 \%$. With a mild drop to $47.69 \%$ only for one day, the GRSI continued to stay at $50 \%$ till the end of the observed period.

When comparing the trend of the daily new cases, it is seen that the country was able to contain the first few clusters successfully when the country GRSI was going at $100 \%$. It should also be noted that the large clusters such as the Kandakadu have occurred at times when the SI had been above $50 \%$. With the reduction of daily new cases, it was logical to reduce the level of stringency, as seen in the Figure 2. However, this seems to have changed after the occurrence of a large number of COvid-19 cases all of a sudden. A rise of GRSI of around $8 \%$ was seen within a day of the occurrence of Minuwangoda cluster. Within 28 days of the onset of the Minuwangoda cluster, the GRSI stabilized just below $50 \%$ of GRSI, giving Sri Lanka GRSI curve a "gutter". Another striking feature that could be seen is that the large spikes of daily cases being reported, as never before, at times when GRSI.

Having observed the Sri Lankan scenario, he countries in Block 1, those who first contacted the disease were studied.

When looking at China, a striking feature is that despite the large wave of Covid-19 cases in early 2020, the country has been able to maintain quite a flat base up to date. In contrast, China, continued to maintain a GRSI close to $80 \%$ up to the end of September. Since then, much lesser GRSI levels with frequent gutters are seen.

Unlike China, South Korea has several large waves of cases, one even continues to rise to date. After rising to a peak above $80 \%$ over a couple of months, GRSI dropped to stabilize between $40-60 \%$.

The pattern of Sri Lanka with those of countries in Block 2, the members of the South Asian Association for Regional Cooperation (SAARC) region will be compared below.

One characteristic feature observed in the above chart comparing the GRSI of seven SAARC countries was the sharp rise of GRSI observed in March 2020. It should be noted that only India and Sri Lanka scored $100 \%$ of the GRSI. India could maintain the GRSI around $80 \%$ since it drops from $100 \%$, except towards the gutter observed between September to November. When comparing with the gutter experienced in the curve for Sri Lanka, three such smaller gutters were observed in the curve of Pakistan. Pakistan never reached $100 \% \mathrm{GRSI}$, the highest point reached being around $95 \%$. However, except for a drop to around above $60 \%$ in May - June, Bangladesh was able to sustain the GRSI at $80 \%$ to date, which is the highest recorded GRSI by the time of the final date of reporting. Afghanistan, reached a GRSI of over $80 \%$, which is its highest reached, which was maintained till June 10 , however subsequently, a 
stepwise decline of the GRSI to reach around $10 \%$ by the end of the reporting period. Bhutan was the only country in the region that had around $80 \% \mathrm{GRSI}$, which only dropped to $65 \%$ over the last week of November.

It should be noted that the axis showing the number of Covid-19 cases among the displayed SAARC member states are quite variable. For example, Bhutan has the lowest number of Covid-19 cases reported per day, even the highest not going beyond 40 cases per day. In contrast, India and Pakistan recorded daily cases even going close to 12,000 . Thus, the comparisons based on the number of cases between these figures must be done with caution, which is not the intended purpose of these charts. Except for Afghanistan, which has let the stringency fall below $20 \%$, even with continuing case numbers, all other five countries have been able to maintain GRSI around $60 \%$ irrespective of the epidemiological trend. This is a worryingly a quite reckless pattern observed in Sri Lanka, which let the GRSI fall below $30 \%$ until it was pushed up only up to $50 \%$ after a large spike of cases was reported. The countries in Block 3 , the more affluent counterparts will be examined in the next section.

Both the USA and UK show that they have been able to maintain around 70 - 80\% GRSI values, except in the initial two months. Nevertheless, the case numbers have grown in three waves in the case of the USA and two large waves in the UK.

In contrast, both Australia and New Zealand shows a wave-like pattern in the GRSI values, synchronous with the waves of cases observed. This is clearer for New Zealand than for Australia, which has allowed the GRSI to fall relatively low while revamping it up with the rising caseload.

Considering all the above facts, several vital points could be discussed. Firstly, GRSI could be a versatile tool that the policymakers could use to have an independent insight into the level of stringency of their own decisions (Hale et al. 2020b). In this era of the internet of things and Covid-19 Pandemic, remote monitoring of country policy decisions has become not only feasible and cost effective, but also safe. Since policy makers commenting on their own decisions, as well as their stringency will not only be politically incorrect but also be scientifically unsound, more independent mechanisms such as GRSI could be used for this purpose.

Secondly, the governments need to be aware of the "stringency fatigue" that is observed as gutters, which have been a common feature across many counties. This stringency fatigue could occur as a result of competing interests that the governments may have to respond to. For example, economic impacts of lockdown are potential, much legitimate yet conflicts of interests that governments may have to work with, when looking at solely from a mobility and outbreak spread is considered (Cross et al. 2020). While it is essential to loosen up the restrictions on mobility, this should be based on sound epidemiological evidence. For example, even after recording a massive peak of cases over a short period, when GRSI was well below 30\%, the government mechanisms Sri Lank have not been able to raise the GRSI value above $50 \%$. Several arguments are given for this. Firstly, the economic burden of a rise of GRSI. Secondly, the disease is still confined to a localized area, which lead to a lockdown of the affected Western Province. 
Both are valid arguments (Epidemiology Unit 2020). However, the point is that all possible evidence must be considered by the governments before making critical decisions concerning public health.

Thirdly, a risk-based stringency approach seems to be most suited. The stringency measures must be proportional to the risk. Let's take the example of Sri Lanka. When the country was managing a few localized clusters, the stringency has been at its peak. However, when the country is facing the largest cluster with blossoming subclusters across the country, it has not been able to increase the stringency beyond $50 \%$. Probably, this is an example of how things should not have been done in a risk-based manner. In contrast, New Zealand appears to be providing a good example of doing things better using a risk-based stringency approach. New Zealand brought down its stringency with decreasing case numbers, however when a large number of cases are reported, they were able to raise the stringency levels back. Subsequently, with dropping case numbers, New Zealanders were able to downscale the measures. This could be one contributor of New Zealand's success in curtailing the Covid-19 pandemic so far (Jefferies et al. 2020).

There are certain limitations of the current study which needs to be kept in mind. Firstly, the relative importance of sub-indicators which make up the GRSI need to be taken into consideration in a deeper analysis. Secondly, policies related to the mobility are much likely to be influenced by other broader economic and health policies. This interdependence needs to be taken into consideration in future research. Thirdly, the GRSI measures the existence of a policy, not necessarily the adherence and compliance. These latter will vary with mode of implementation, legal measures and culture. Fourthly, the

absolute number of cases was used in the current study, however, per capita number of cases would have been a better measure of diseases. For example, comparing India and Bhutan stretches the meaning in talking of absolute number of cases. These limitations need to be overcome in future more detailed work, including using more advanced statistical methodologies, where appropriate.

\section{Conclusion}

Considering the status of Sri Lanka, as of $30^{\text {th }}$ November 2020, it is evident that the current GRSI values adopted by Sri Lanka appear to be suboptimal compared to the level of risk that the country is exposed to as evident from the case trend. In this backdrop, rapid uplifting of the stringency of the country, at least until the case number starts to decline is recommended. Economic repercussions of such policy decisions are quite valid and legitimate; however, the public health consequences of the widespread Covid-19 transmission can have much more sustained and long-lasting impacts on the economy, which could be much devastating. After all, the health of the public is an unnegotiable priority, since the economic gains of an unhealthy population will for sure leave an empty treasury.

\section{Declarations}

Acknowledgement: 
The valuable feedback on the article provided by Prof. Glenn Withers from Australia is acknowledged with thanks.

\section{Conflict of Interest:}

Authors declare no conflict of interest.

\section{References}

Cross, Megan, Shu-Kay Ng, and Paul Scuffham. 2020. "Trading Health for Wealth: The Effect of COVID-19 Response Stringency." International Journal of Environmental Research and Public Health 17(23):8725. doi: 10.3390/ijerph17238725.

Epidemiology Unit. 2020. “Epidemiology Unit." Retrieved December 5, 2020 (http://epid.gov.lk/web/index.php?lang=en).

Erdbrink, Thomas, and Christina Anderson. 2020. 'Life Has to Go On': How Sweden Has Faced the Virus Without a Lockdown." The New York Times, April 28.

Ferraresi, Massimiliano, Christos Kotsogiannis, Leonzio Rizzo, and Riccardo Secomandi. 2020. "The 'Great Lockdown' and Its Determinants." Economics Letters 197:109628. doi:

10.1016/j.econlet.2020.109628.

FT Visual \& Data Journalism Team. 2020. “Lockdowns Compared: Tracking Governments' Coronavirus Responses." Retrieved December 5, 2020 (https://ig.ft.com/coronavirus-lockdowns).

Hale, Thomas, Noam Angrist, Emily Cameron-Blake, Laura Hallas, Kira Beatriz, Saptarshi Majumadar, Anna Petherick, Toby Phillips, Helen Tatlow, and Samuel Webster. 2020a. Oxford COVID-19 Government Response Tracker Blavatnik School of Government.

Hale, Thomas, Noam Angrist, Emily Cameron-Blake, Laura Hallas, Kira Beatriz, Saptarshi Majumadar, Anna Petherick, Toby Phillips, Helen Tatlow, and Samuel Webster. 2020b. Variation in Government Responses to Covid-19. Version 8.0 Blavatnik School of Government Working Paper.

Jayaratne, Kapila, Carukshi Arambepola, and Shamini Prathapan. 2020. "Flattening the Epidemic Curve of COVID-19 in Sri Lanka: The Public Health Response." Journal of the College of Community Physicians of Sri Lanka 26(5). doi: 10.4038/jccpsl.v26i5.8390.

Jefferies, Sarah, Nigel French, Charlotte Gilkison, Giles Graham, Virginia Hope, Jonathan Marshall, Caroline McElnay, Andrea McNeill, Petra Muellner, Shevaun Paine, Namrata Prasad, Julia Scott, Jillian Sherwood, Liang Yang, and Patricia Priest. 2020. "COVID-19 in New Zealand and the Impact of the National Response: A Descriptive Epidemiological Study." The Lancet Public Health 5(11):e612-23. doi: 10.1016/S2468-2667(20)30225-5. 
Potter, Christopher C., and Jennifer Harries. 2006. "The Determinants of Policy Effectiveness." 84(11):1.

Roser, Max, Hannah Ritchie, Esteban Ortiz-Ospina, and Joe Hasell. 2020. “Coronavirus Pandemic (COVID19)." Our World in Data.

World Health Organization. 2020a. "IHR Emergency Committee on Novel Coronavirus (2019-NCoV)." Retrieved December 5, 2020 (https://www.who.int/director-general/speeches/detail/who-director-generals-statement-on-ihr-emergency-committee-on-novel-coronavirus-(2019-ncov)).

World Health Organization. 2020b. "WHO Coronavirus Disease (COVID-19) Dashboard." Retrieved December 5, 2020 (https://covid19.who.int).

World Health Organization. 2020c. "WHO Director-General's Opening Remarks at the Media Briefing on COVID-19 - 11 March 2020." Retrieved December 5, 2020 (https://www.who.int/directorgeneral/speeches/detail/who-director-general-s-opening-remarks-at-the-media-briefing-on-covid-19--11march-2020).

\section{Figures}




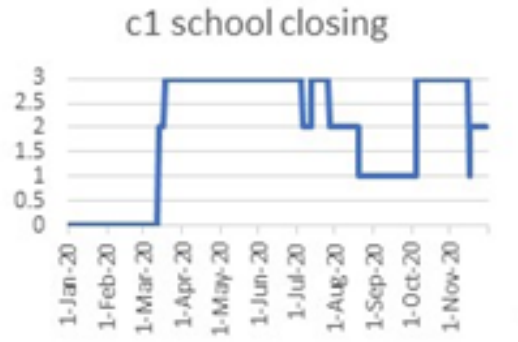

c3 cancelation of public events

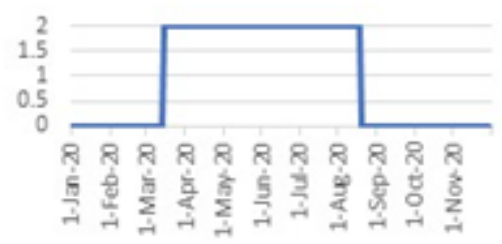

c5 close public transport
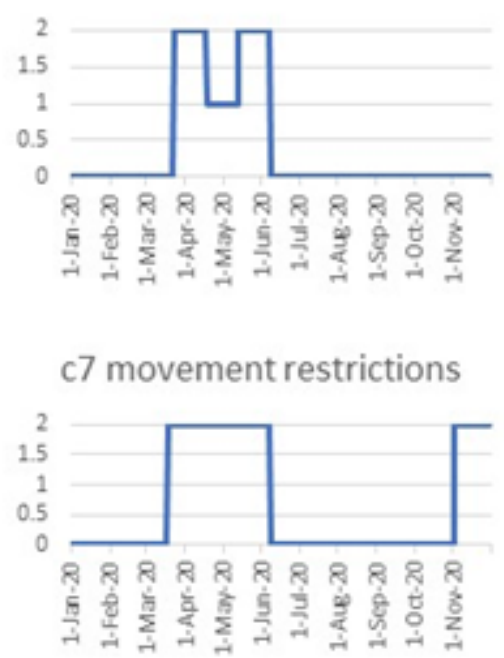

$\mathrm{H} 1$ public information

campaigns

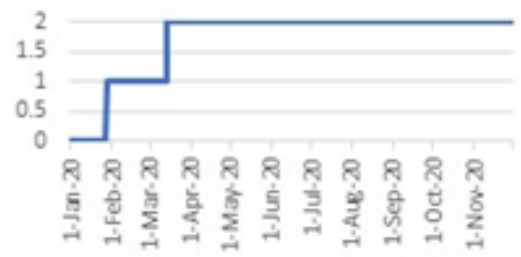

\section{Figure 1}

Distribution of Sub-Indicators of the Government Response Stringency Index for Sri Lanka 


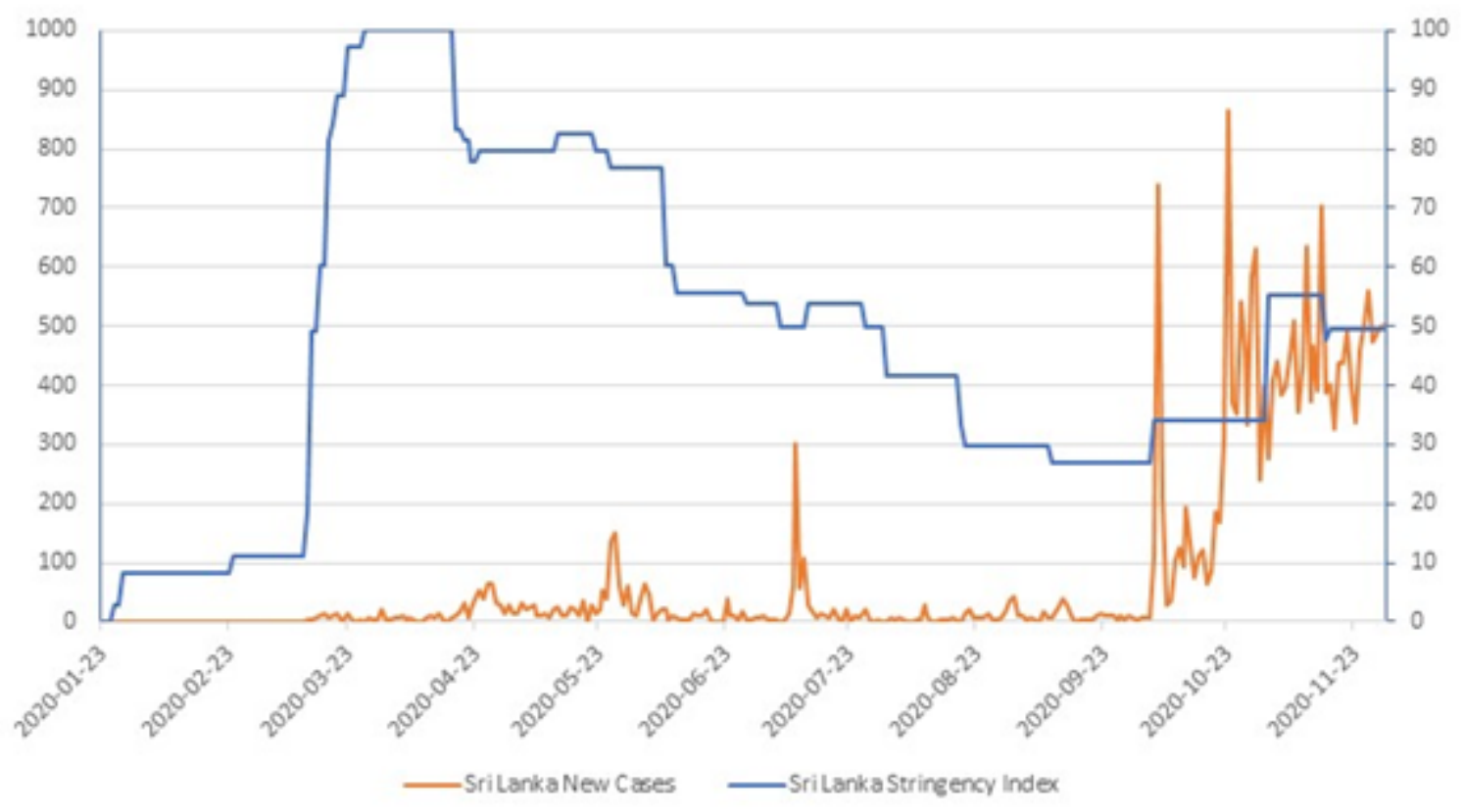

Figure 2

Daily Distribution of Covid-19 New Cases and Stringency Index in Sri Lanka 


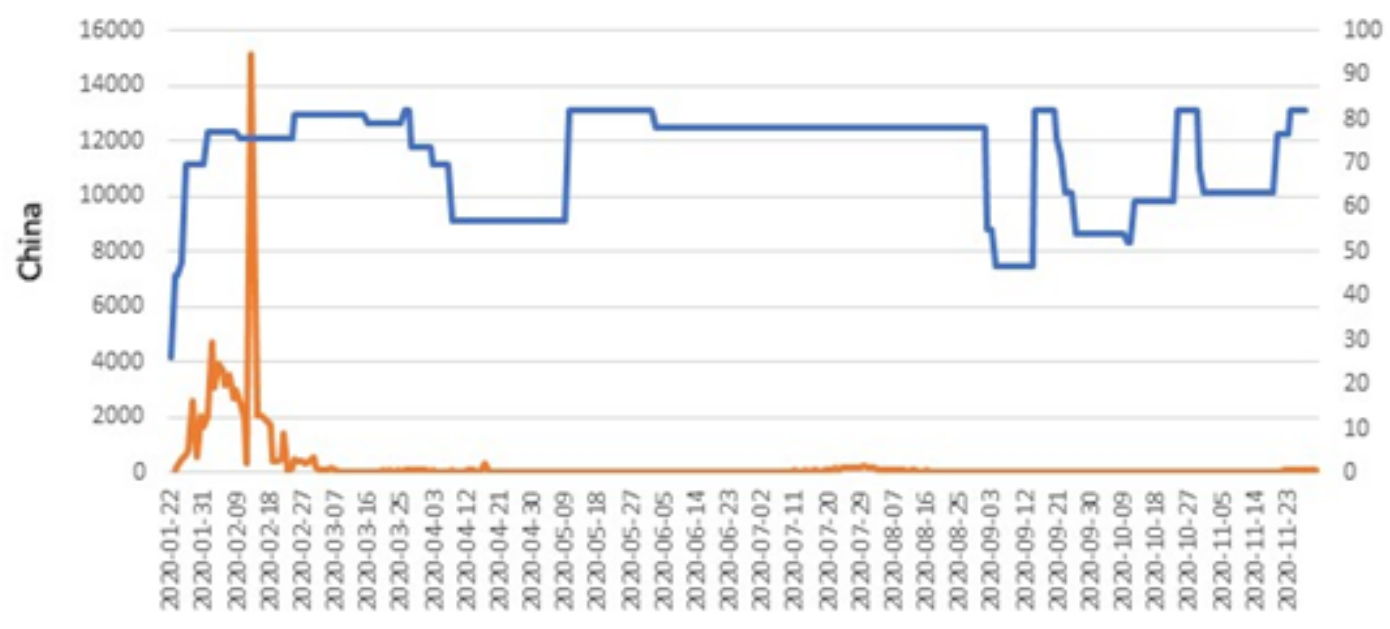

Chinanew cases Chinastringency index

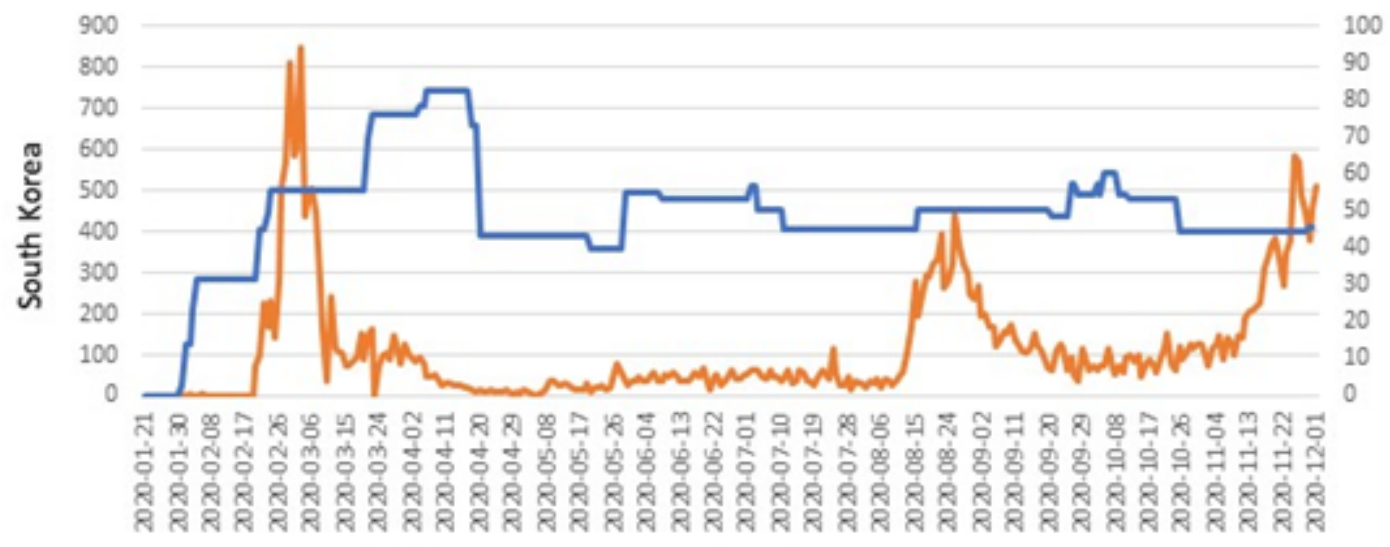

-South Koreanew cases - - South Koreastringency index

Figure 3

Daily Distribution of New Covid-19 Cases and Stringency Index in China and South Korea 

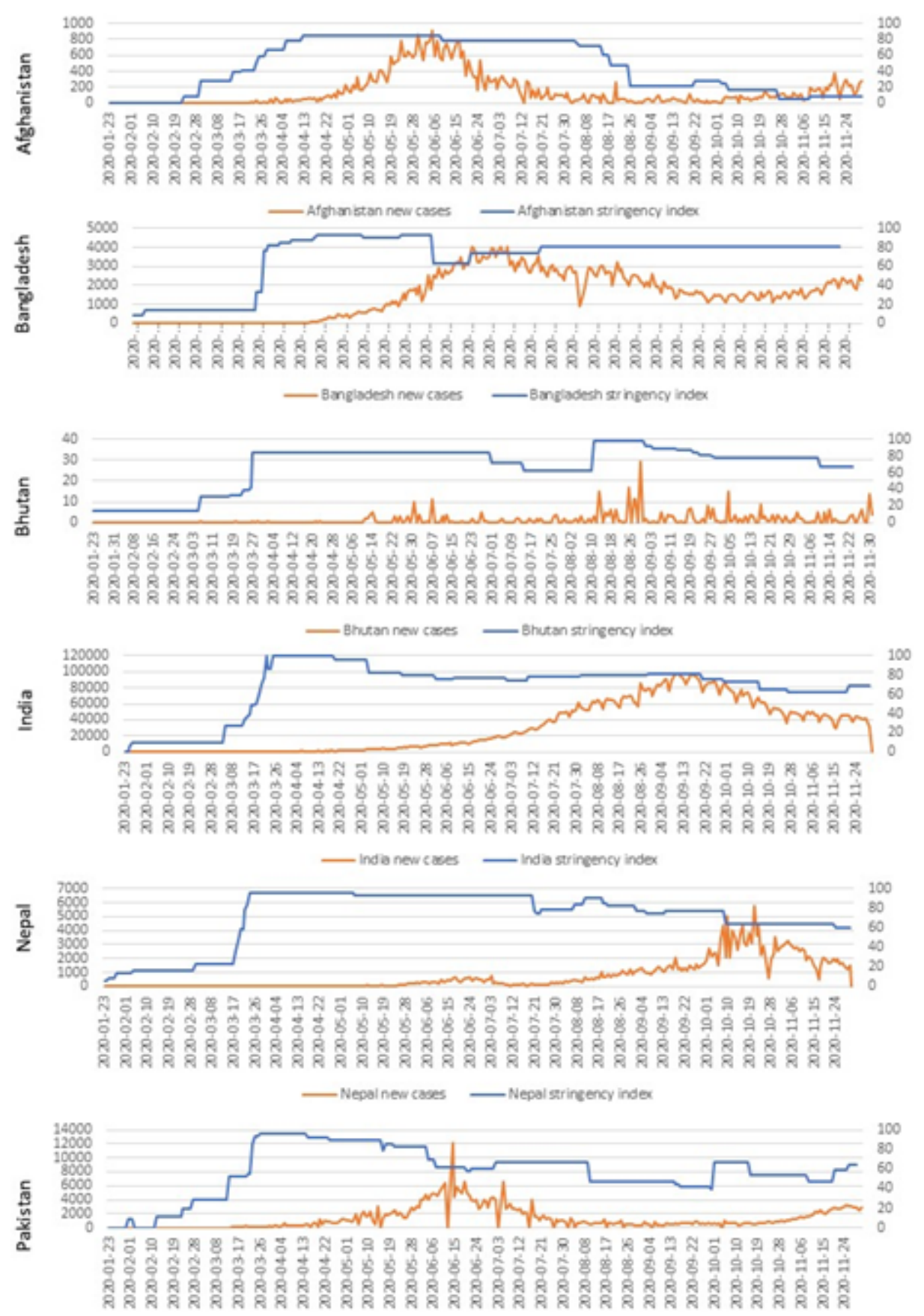

_- pasistan new cases _- pakistan at ingency inder

Figure 4

Daily Distribution of New Covid-19 Cases and Stringency Index in SAARC Countries other than Sri Lanka and the Maldives 


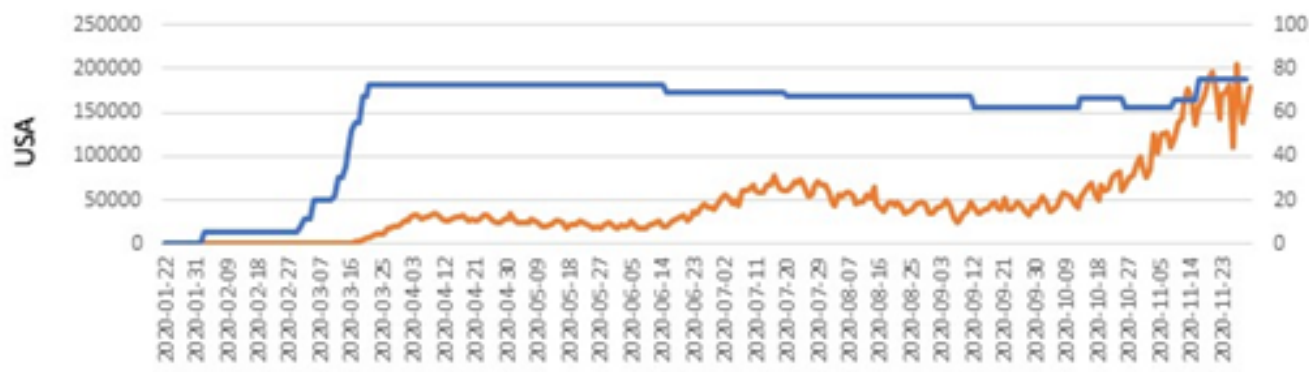

_uSA new cases _usA stringency inder

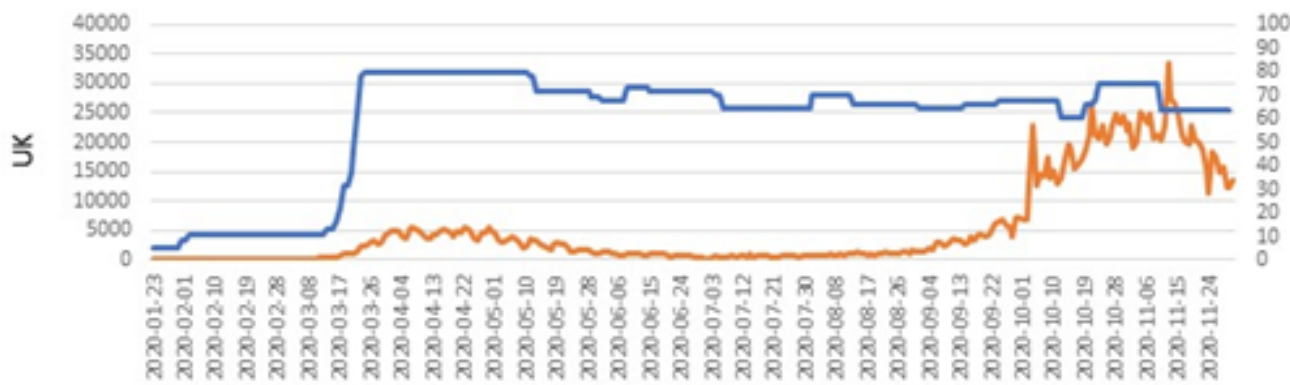

-UK new cases _uK singency index

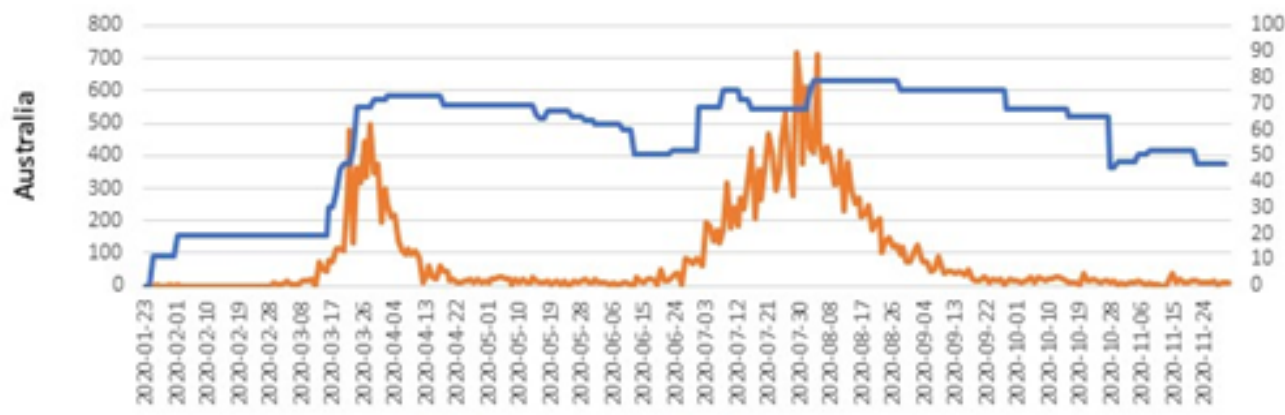

- Australa new cares - Australa stringency index

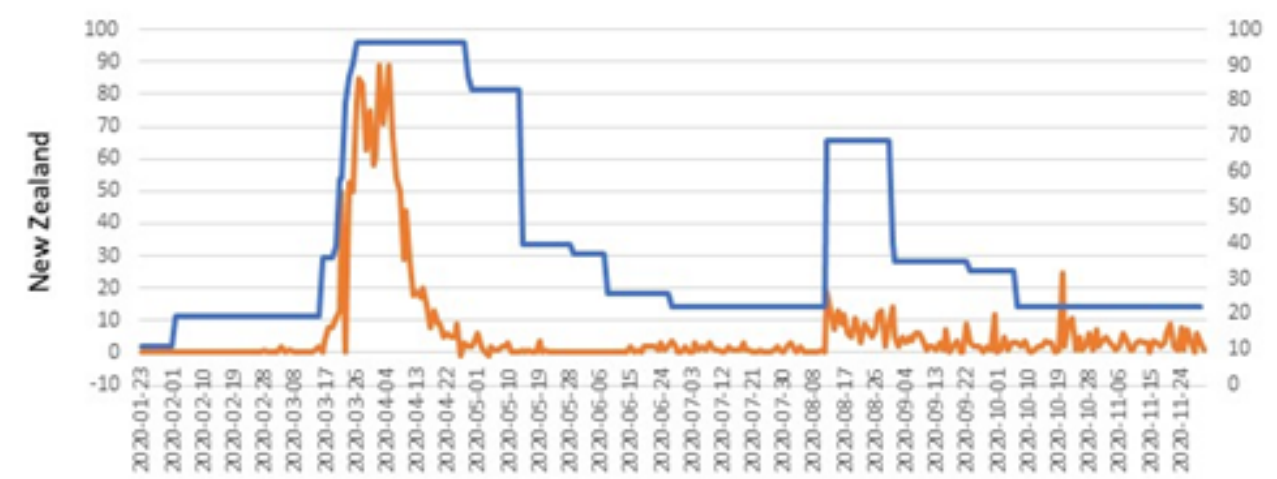

-New Zealand new cases _ New Zealand stringency index

\section{Figure 5}

Daily Distribution of Covid-19 Cases and Stringency Index in Selected Affluent Countries

\section{Supplementary Files}

This is a list of supplementary files associated with this preprint. Click to download. 
- ICSBE2020Presentation177Wijesekaraetal.pdf 